\title{
Lissencephaly Gene (LIS1) Expression in the CNS Suggests a Role in Neuronal Migration
}

\author{
Orly Reiner, ${ }^{1}$ Urs Albrecht, ${ }^{2}$ Marissa Gordon, ${ }^{3}$ Kimberly A. Chianese, ${ }^{3}$ Calvin Wong, ${ }^{2}$ Orit Gal-Gerber, ${ }^{1}$ Tamar \\ Sapir, ${ }_{1}^{1}$ Linda D. Siracusa, ${ }^{3}$ Arthur M. Buchberg, ${ }^{3}$ C. Thomas Caskey, ${ }^{4}$ and Gregor Eichele ${ }^{2}$ \\ 'Department of Molecular Genetics and Virology, The Weizmann Institute of Science, Rehovot 76100, Israel, \\ ${ }^{2}$ Departments of Biochemistry and Neuroscience, Baylor College of Medicine, Houston, Texas 77030, 3Jefferson \\ Cancer Institute, Department of Microbiology and Immunology, Jefferson Medical College, Philadelphia, \\ Pennsylvania 19107, and ${ }^{4}$ Department of Molecular and Human Genetics and Howard Hughes Medical Institute, \\ Baylor College of Medicine, Houston, Texas 77030
}

\begin{abstract}
Miller-Dieker lissencephaly syndrome (MDS) is a human developmental brain malformation caused by neuronal migration defects resulting in abnormal layering of the cerebral cortex. LIS1, the gene defective in MDS, encodes a subunit of brain platelet-activating factor (PAF) acetylhydrolase which inactivates PAF, a neuroregulatory molecule. We have isolated murine cDNAs homologous to human LIS1 and mapped these to three different chromosomal loci (Lis1, Lis3, Lis4). The predicted sequences of murine Lis1 protein and its human homolog LIS1 are virtually identical. In the developing mouse and human, Lis1 and LIS1 genes were strongly expressed in the cortical plate. In the adult mouse Lis1 transcripts were abundant in cortex and hippocampus. The direct correlation between cortical defects in MDS patients and Lis1 expression in the murine cortex suggest that the mouse is a model system suitable to study the mechanistic basis of this intriguing genetic disease.

Sequence data are deposited as L25108 for mouse Lis1 CDNA and L25109 for mouse Lis3-4 cDNA.

[Key words: cerebral cortex, cerebellum, neurogenesis, Miller-Dieker syndrome, lissencephaly, platelet-activating factor acetylhydrolase, in situ hybridization]
\end{abstract}

Lissencephaly is a human brain malformation characterized by a smooth cerebral surface and a disordered organization of the cortical layers believed to result from a defect in neuronal migration (Barth, 1987; Aicardi, 1989). Two types of lissencephaly have been defined (Aicardi, 1991; Kuchelmeister et al., 1993). In type I, the cortex consists of four layers whereas in type II the cortex is unlayered. In the case of type I lissencephaly, the cortex consists of the molecular layer (layer 1), layer 2 harboring

Received Sept. 9, 1994; revised Nov. 28, 1994; accepted Dec. 28, 1994.

We thank Drs. S. McConnel, J. Helms, P. Neuman, B.-Z. Shilo, and A. BenZeev for critical reading of the manuscript, Dr. Y. Citri for the mouse brain cDNA library and Dr. B. Lutz for expert advice. This research was supported by the National Institute of Health and the McKnight Endowment Fund for Neuroscience (G.E.), NIH grant CA58586 (A.M.B.), the Green Research Fund and the Forchheimer Center (O.R.), the Baylor Human Genome Center, and the Department of Energy. C.T.C. is an investigator with the Howard Hughes Medical Institute. O.R. is incumbent of Aser Rothstein career development chair in genetic diseases.

Correspondence should be addressed to Dr. Gregor Eichele, Department of Biochemistry, Baylor College of Medicine, One Baylor Plaza, Houston, TX 77030 , or Dr. Orly Reiner al the above address.

Copyright $(1995$ Society for Neuroscience $0270-6474 / 95 / 153730-09 \$ 05.00 / 0$ neurons with a morphology normally seen in layers 3,5 and 6 . Layer 3 in type I lissencephaly is cell sparse, and layer 4 contains neurons that are misplaced and seem to be arrested in their migration (Barth, 1987; Aicardi, 1989). Examples of clinical manifestations of type I and type II lissencephaly are the MillerDieker syndrome (Miller, 1963; Dieker et al., 1969) and the Walker-Warburg syndrome, respectively. A gene termed LISI that is involved in Miller-Dieker syndrome has recently been isolated and is located on human chromosome 17p13.3 (Reiner et al., 1993). LISI encodes a polypeptide with "WD-40 repeats" found in proteins with diverse functions (Duronio et al., 1992). It has now been shown that the bovine homolog of LIS1 is a subunit of the brain platelet activating factor acetylhydrolasc (Hattori et al., 1994). This trimeric enzyme inactivates plateletactivating factor, an alkyl-ether phospholipid implicated in various aspects of neural development (Kornecki and Ehrlich, 1988) and in neuronal function (Bito et al., 1992; Clark et al., 1992; Kato et al., 1994).

LISI is so far the only gene isolated whose mutation causes abnormal layering of the cortex. Therefore, the study of LISI gene expression may shed light on the molecular and cellular mechanisms of neuronal migration which is required for proper cortical development. We have chosen the mouse as an experimental system to elucidate the potential function of lissencephaly genes in brain development. Toward this objective, we have isolated and characterized by map position and DNA sequence mouse cDNAs that hybridized to human LISI. The expression of each cDNA was studied by Northern analysis and the distribution of LisI mRNA, the mouse homolog of human LISI, was studied by in situ hybridization in the developing mouse central nervous system. An expression analysis of LISI in human fetal brain was also carried out. The studies to be reported here led us to the conclusion that the human LISI and mouse LisI are expressed, in part, in regions of the embryo that undergo neuronal migration.

\section{Materials and Methods}

DNA analysis. $5 \times 10^{6}$ plaque forming units (pfu) of a lambda ZAPII library, and $10^{6}$ pfu of a lambda gt 11 library were screened. Both libraries were generated from adult mouse brain. Sequencing was done cssentially as described (Fu et al., 1993) with slight modifications. cDNA fragments were subcloned into BlueScript II $\mathrm{KS}^{+}$(Stratagene, La Jolla, CA), and plasmid DNA was prepared using Qiagen kits (QIAGEN, Chatsworth, CA). Inserts were gel-purified using Geneclean (BIO 101, La Jolla, CA), sonicated and size-selected by agarose gel electro- 
Table 1. Probes used in genetic mapping

\begin{tabular}{|c|c|c|c|c|c|c|}
\hline \multirow[b]{2}{*}{ Locus } & \multirow[b]{2}{*}{ Gene name } & \multirow[b]{2}{*}{ Probe } & \multirow[b]{2}{*}{ R.E. } & \multicolumn{2}{|l|}{ Size } & \multirow[b]{2}{*}{ Reference } \\
\hline & & & & $\mathrm{AEJ} / \mathrm{Gn}$ & M. spretus & \\
\hline \multicolumn{7}{|l|}{ A. RFLPs } \\
\hline Acrb & Acetylcholine receptor $\beta$ & pAchrb & TaqI & $8.8,1.7$ & $4.8,3.1,1.7$ & Heidmann et al. (1986) \\
\hline$E v i 2 a$ & $\begin{array}{l}\text { Ecotropic viral integra- } \\
\text { tion- } 2 \mathrm{a}\end{array}$ & $\mathrm{pBK} 4$ & $B g l I$ & 18.4 & $\overline{13.6}$ & Buchberg et al. (1990) \\
\hline Lis & Lissencephaly & LIS-ORF & Pst $\mathrm{I}$ & $9.1,4.6,3.4,1.7$ & $10.9,1.4,0.9^{h}$ & Reiner et al. (1993) \\
\hline$N g f b$ & Nerve growth factor $\beta$ & pmngf6 & HindIII & 6.9 & 4.9 & Scott et al (1983) \\
\hline$T p i-r s 2$ & $\begin{array}{l}\text { Triose phosphate } \\
\text { isomerase, related } \\
\text { sequence-2 }\end{array}$ & pHTPI-5A & HindIII & & $\overline{3.5}$ & Siracusa et al. (1991) \\
\hline$T p i-r s 3$ & $\begin{array}{l}\text { Triose phosphate isomer- } \\
\text { ase, related sequence- } 3\end{array}$ & pHTPI-5A & HindIII & & 20 & Siracusa et al. (1991) \\
\hline D7Mit27 & & DNA segme & & 240 & 220 & Dietrich et al. (1992a,b) \\
\hline DIIMit 7 & & DNA segme & 7 & 146 & 180 & Dietrich et al. (1992a,b) \\
\hline
\end{tabular}

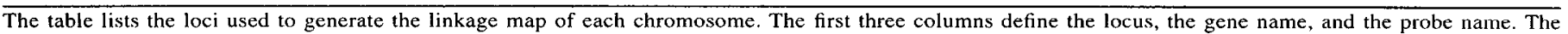

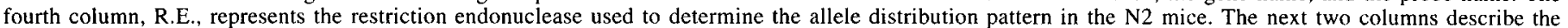

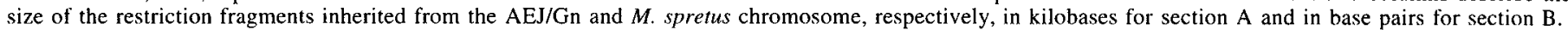

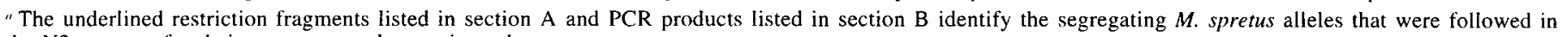
the N2 progeny for their presence or absence in each mouse.

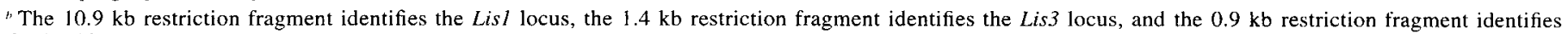
the Lis4 locus.

phoresis. DNA fragments sized $0.9-1.5 \mathrm{~kb}$ were recovered from the gel by Geneclean, and the DNA ends were made blunt ended by mung bean nuclease and T4 DNA polymerase (Pharmacia LKB Biotechnology, Piscataway, NJ). DNA fragments were ligated into an M13 vector. DNA from white plaques was isolated and sequenced with dideoxynucleotide termination reactions. Sequencing reactions were prepared on a Biomek 1000 Automated Labstation according to a cycle sequencing protocol. Reactions were analyzed on an automated DNA sequencer (ABI 373) (Applied Biosystems, Foster City, CA) with fluorescently labeled oligonucleotide primers. Sequence ambiguities were then resolved by ABI dye terminators with the use of specific primers. Sequence information was assembled with SEQUENCE ASSEMBLY MANAGER software (Molecular Biology Computational Resource, Department of Cell Biology, Baylor College of Medicine). Southern and northern blot analyses were done by standard protocols (Sambrook et al., 1989). Northern blots were from adult mouse tissues and were purchased (Clontech, Palo Alto, CA).

Generation of specific probes. For mouse probes, the probe from the open reading frame was a 285 bp fragment generated by PCR using primers 5'-CTGACGTCCCACATCTTAATAG-3' and 5'-GCTACTGTGTGAAGACATTCAC-3'; the Lis3-4 3'-specific probe was a 262 bp fragment generated by PCR using primers 5'-GCACTTCTACCAGCTGAACC- $3^{\prime}$ and 5'-GCAGCCATGAAGTAGCAGTG-3'; the probe for Lis1 3'-specific probe was a 296 bp fragment generated by restriction digest of Lisl by XhoI and NheI.

For human probes, the specific probe for the LISI $3^{\prime}$ end was a 521 bp fragment generated by restriction enzyme cleavage of clone 6-1 using EcoRI and $B s p \mathrm{HI}$, subcloned in BlueScriptII $\mathrm{KS}+$; the open reading frame probe used for screening mouse cDNA libraries was an NcoIEcoRI fragment derived from clone 47.

$R N A$ in situ hybridization. Embryo collection, sectioning and in situ hybridization were performed as described previously (Sundin et al., 1990). Antisense and sense RNA probes labeled with $\alpha^{35}$ S-UTP (1000 $\mathrm{Ci} / \mathrm{mmol}$, Amersham, Arlington Heights, IL) were synthesized with T7 or T3 RNA polymerase using EcoRI- or HindIII-linearized LisI and Lis3-4 ORF constructs, or EcoRI- and Sall-linearized Lis3-4 templates (see Fig. 2). Hybridization was done overnight at $50^{\circ} \mathrm{C}$ with a probe concentration of 0.24 or $0.09 \mathrm{ng} / \mu \mathrm{l}$, depending on the probe. Posthy- bridization treatments were as follows: (1) two washes in $50 \%$ formamide, $2 \times \mathrm{SSC}, 20 \mathrm{~mm} \beta$-mercaptoethanol (FSH) at $63.5^{\circ} \mathrm{C}$ for $30 \mathrm{~min}$, (2) digestion with $10 \mu \mathrm{g} / \mathrm{ml}$ RNase $\mathrm{A}$ in $4 \times \mathrm{SSC}, 20 \mathrm{~mm}$ Tris- $\mathrm{HCl}(\mathrm{pH}$ 7.6), $1 \mathrm{~mm}$ EDTA at $37^{\circ} \mathrm{C}$ for $30 \mathrm{~min}$, and (3) two washes in $\mathrm{FSH}$ at $63.5^{\circ} \mathrm{C}$ for $45 \mathrm{~min}$. Slides were dipped in Kodak NTB-2 emulsion and exposed for $10 \mathrm{~d}$. Nissl staining with thionin was done as described (Putt, 1972). Early stages of mouse embryos (E10.5-E13.5) were sagittally sectioned, and later stages (E14.5-E16.5) were sectioned coronal. For stages after El6.5, brains were dissected and coronally sectioned except for the adult brains which were sectioned in the horizontal plane.

Genetic mapping. The interspecific backcross between (AEJ/Gn- $a$ $b p^{\mathrm{H} / a} b p^{\mathrm{H}} \times$ Mus spretus $) \mathrm{F} 1 \times \mathrm{AEJ} / \mathrm{Gn}-a b p^{\mathrm{H} / a} b p^{\mathrm{H}}$ has been previously described (Marini et al., 1993). Genomic DNA extractions, restriction endonuclease digestions, agarose gel electrophoresis, and Southern blot transfers, hybridizations, and washes were as described previously (Ma et al., 1993). DNA oligonucleotides used for detecting simple sequence length polymorphism (SSLP) markers (Dietrich et al., 1992a) were made using an Applied Biosystems Model 394 DNA synthesizer. SSLP markers were detected by amplifying genomic DNA from N2 animals using the specified DNA oligonucleotide pairs and Taq DNA polymerase as described (Ma et al., 1993).

\section{Results}

\section{Genetic mapping of LIS clones in the mouse}

We mapped the murine $L i$ s genomic loci and afterwards isolated cDNA clones. Genomic DNA from parents of the interspecific backcross (AEJ/Gn and $M$. spretus) was digested with several restriction endonucleases and analyzed by Southern blot hybridization. The open reading frame of the human LISI CDNA was used to identify restriction fragment length polymorphisms (RFLPs), useful for establishing the map location. Three polymorphic restriction fragments were identified with PstI. The segregation patterns of these three polymorphic restriction fragments werc followed in random subsets of 195 N2 backcross progeny. Segregation analysis revealed that the three restriction 
A

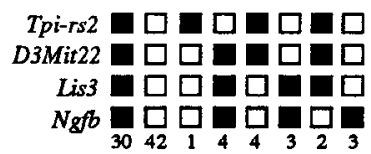

B

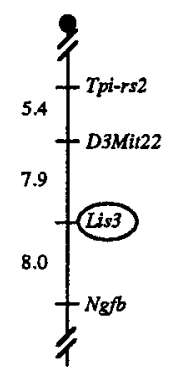

Chr 3
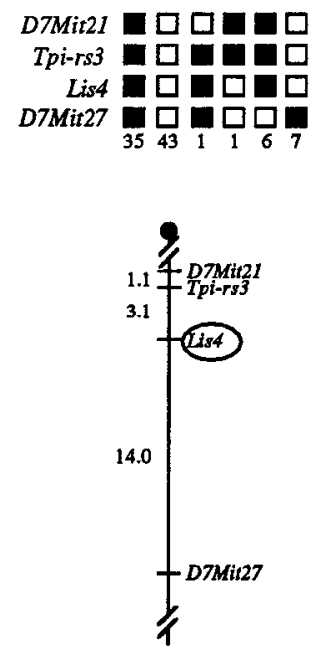

Chr 7
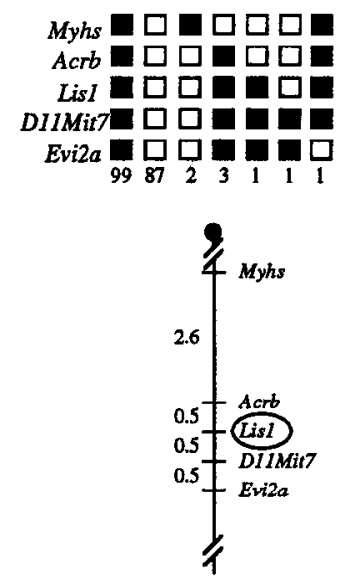

Chr 11

Figure 1. Genetic mapping in the mouse. A, Summary of the results of the interspecific backeross analysis for chromosomes 3, 7, and 11, respectively. Genes mapped in the analysis are listed on the left. Each column represents the chromosome identified in the N2 progeny inherited from the $(\mathrm{AEJ} / \mathrm{Gn} \times M$. spretus $) \mathrm{F} 1$ parent. The solid boxes represent the AEJ/Gn allele and the open boxes represent the $M$. spretus allele. The number of each type of chromosome identified in the backcross progeny is listed at the bottom. Haplotype analysis of chromosomes 3,7 , and 11 were performed using a subset of the N2 offspring in which each locus was scored. The order of the loci and the ratio of the number of recombinants to the total number of $\mathrm{N} 2$ offspring examined for each locus are as follows: chromosome 3, Tpi-rs $2-5 / 92-$ D3Mit22 - 7/88 - Lis $3-12 / 150$ - Ngfb; chromosome 7, D7Mit21 - 1/93 - Tpi-rs3 - 5/161 - Lis4 - 13/93 - D7Mit27; chromosome 11, Myhs - 5/194 - Acrb - 1/194 Lis 1 - 1/194 - DllMit7 - 1/194 - Evi2a. B, Placement of the genes on their respective chromosomes (Chr, chromosome). Genetic localization of Lis3, Lis4, and Lis1 (circled on each chromosome). The figure represents the regions of mouse chromosomes 3, 7, and 11 analyzed in the interspecific backcross. The genes mapped are listed on the right of each chromosome and the genetic map distance (in cMs) between adjacent loci, are listed on the left of each chromosome. The genetic distances between the loci in cM $\pm \mathrm{SE}$ are as follows: chromosome 3, Tpi-rs2 - 5.4 $\pm 2.4-$ D3Mit $22-7.9 \pm 2.9-$ Lis3 $-8.0 \pm 2.2-$ Ngfb; chromosome 7, D7Mit2l - $1.1 \pm 1.1-$ Tpi-rs3 - $3.1 \pm 1.4-$ Lis $4-14 \pm$ 3.6. D7Mit27; chromosome 11, Myls - 2.6 $\pm 1.1-$ Acrb $-0.5 \pm 0.5-$ Lis $1-0.5 \pm 0.5-$ DIIMit $7-0.5 \pm 0.5-$ Evi2a.

fragments segregated independently. Comparison of the segregation patterns with locations of known markers in this mapping panel (Table 1) indicated that these loci mapped to chromosomes 3, 7 and 11 (Fig. 1). The gene order was resolved by minimizing the number of multiple recombinants along the length of each chromosome. It thus appears that the mouse genome contains several Lis genes, reminiscent of the situation in the human genome that contains at least two LIS genes, one on chromosome 17 (LISI) and the other one on chromosome 2 (LIS2, O. Reiner et al., unpublished observations) (Reiner et al., 1993). Hybridizing the $3^{\prime}$ untranslated region of the LisI cDNA (Fig. 2B) and using several differcnt restriction cndonucleases, we detceted a single polymorphic restriction fragment that concordantly segregated with the chromosome 11 locus. Thus, this locus was designated Lisl. The localization of Lis I to mouse chromosome 11 between Acrb and Evi2a is consistent with its position on human chromosome 17. Based on both sequence comparison (see below) and linkage analysis, LisI most likely represents the murine homolog of human LIS1. The restriction polymorphisms detected by the 3' untranslated region of the Lis 3-4 cDNA (Fig. $2 B$ ) identified chromosome 3 and 7 loci. Since the $3^{\prime}$ end of the Lis3-4 cDNA does not share homology with either LIS1 or LIS2, these loci were designated Lis 3 and Lis 4 , respectively, and potentially represent new members of the Lis gene family.

\section{Isolation of mouse Lis clones}

Next, two adult mouse brain cDNA libraries were screened with a probe containing the open reading frame of the human LISI cDNA. Forty cDNAs were isolated and partial sequencing al- lowed classification into three groups. Group 1 cDNAs were designated Lis 1 (Fig. $2 B$ ) because they hybridized to the Lisl locus (see previous section). Group 2 cDNAs were termed Lis 3-4 (Fig. $2 B$ ) and originated from either the Lis3 or the Lis 4 locus. A third group of cDNAs consisted of clones that contained a short $3^{\prime}$ untranslated region with a polyA track located $107 \mathrm{bp}$ after the stop codon (data not shown). These cDNAs were possibly generated by use of alternative polyadenylation sites, thus resembling the previously described short human LISI cDNA (47) (Fig. 2A). One of the group I cDNAs was sequenced and exhibited high nucleotide sequence similarity to the $5^{\prime}$ untranslated region, the open reading frame region, and the $3^{\prime}$ untranslated region of the human LISI cDNA (LISI clone 71, Fig. $2 A, B)$. Since the deduced amino acid sequence of this cDNA was identical to human LISI (except for a methionine substituted by a valine), it was given the name Lisl. Lis3-4 and LisI diverged $71 \mathrm{bp}$ prior to the stop codon, and the predicted amino acid sequence of Lis.3-4 was shorter by 19 amino acids. Moreover, the C-terminal five amino acids of Lis3-4 differed from those of Lisl. The 3' untranslated sequence of Lis3-4 had no similarity to the other Lis clones and contained a mouse repetitive sequence of the B2 family (Bladon and McBurney, 1991). The evolutionary relationship between the human and mouse genes are the focus of continuing studies.

\section{Northern blot analysis in adult mouse tissues}

For Northern analysis of adult mouse RNA two probes specific for cach locus werc uscd (marked in Fig. 2B). Onc probe was derived from the Lisl cDNA ("Lisl probe"), and the second is 
A. Human clones
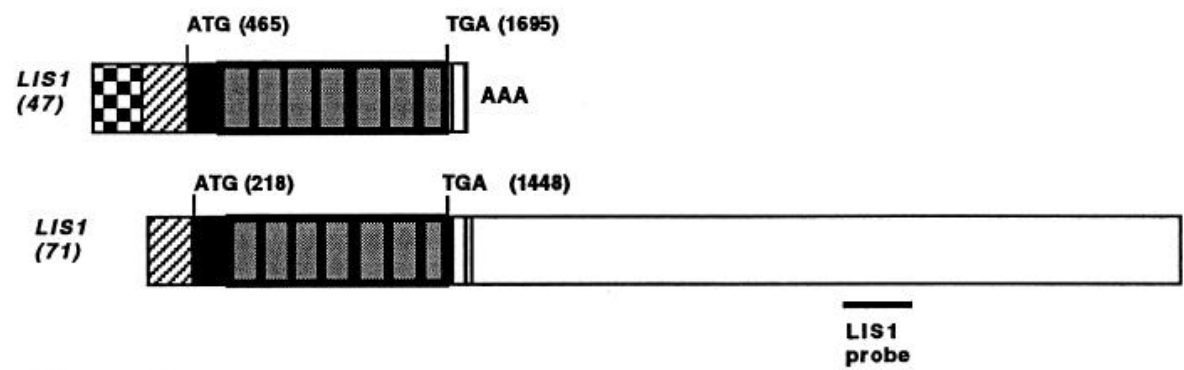

B. Mouse clones

Figure 2. Comparison of the structure of human and mouse Lis cDNAs. Identical shading patterns indicate largely similar nucleotide sequences. The overall nucleotide sequence similarity between mouse LisI and human LISI

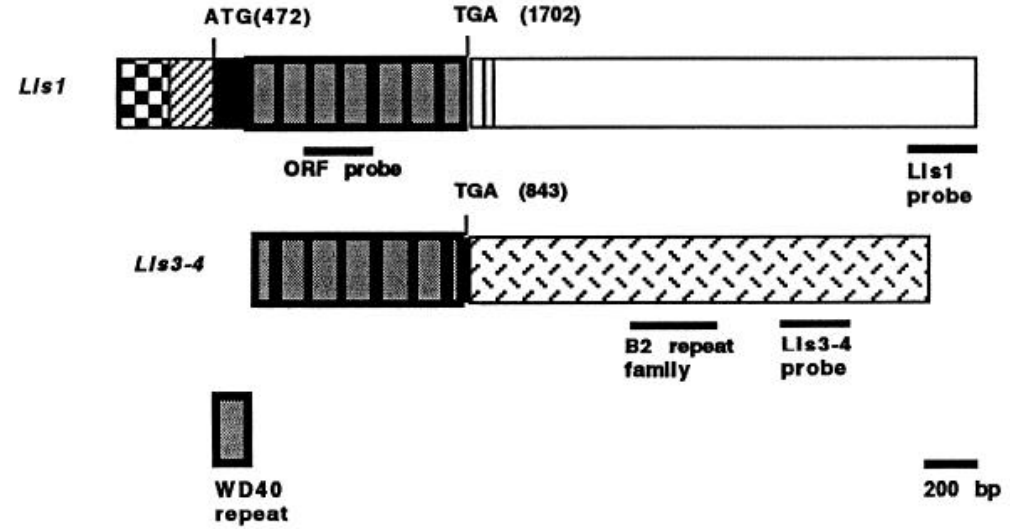
(71) is $89.5 \%$, whereas the overall similarity between these LisI and LISI (47) is 93.3\%. Lis3-4 and LISI (71) are $95 \%$ identical within an open reading frame region extending between nucleotides 575-1376 of LISI. The positions of the starting methionine codon (ATG) and termination codon (TGA) are indicated. For the Lis3-4 cDNA N-terminal sequences and $5^{\prime}$ untranslated sequences have not yet been determined. Mouse B2 repetitive elements are found in the Lis3-4 cDNAs between nucleotides 1036-1289. The WD40 motif repeats are shown. The Lis probes used for Northern blots and in situ hybridization are indicated.

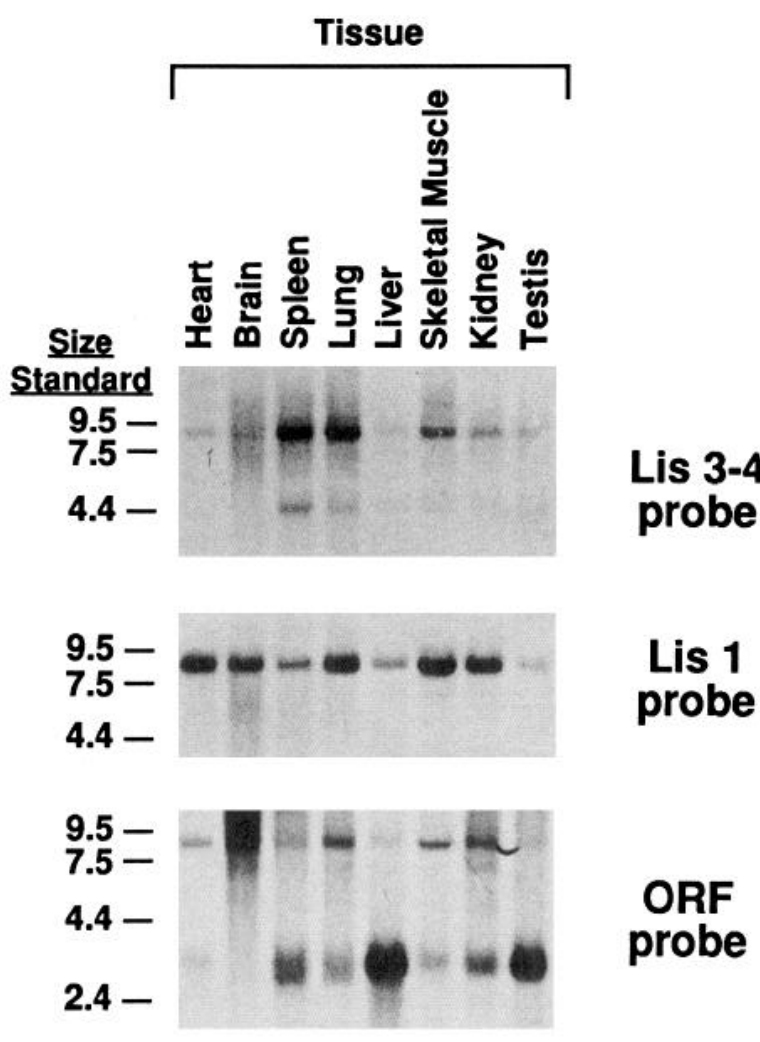

Figure 3. Northern blot analysis of adult mouse tissues. Two micrograms of polyA ${ }^{+}$RNA transferred to nylon membrane (Mouse Multiple Tissue Northern, Clontech) were hybridized to three probes (marked in Fig. 2B), a probe specific for LisI, a probe specific for Lis3-4 and the ORF probe that is common to both cDNAs. Lis3-4 probe detects transcripts of 8 and $4.4 \mathrm{~kb}$ in length, while the LisI probe detects mainly an $8 \mathrm{~kb}$ message. The ORF probe detects messages of 3 and $8 \mathrm{~kb}$ in size.

specific for Lis3-4. Additionally hybridized was a third probe from an open reading frame sequence ("ORF probe") that was shared by all the known murine Lis cDNAs. The analysis demonstrated expression in all tissues tested for each of the specific probes (Fig. 3). The probe specific for Lis3-4 detected two main transcripts of 8 and $4.4 \mathrm{~kb}$ in length with the highest level of expression detected in spleen and lung. In contrast, Lis3-4 expression was low in brain. Interestingly, in skeletal muscle two additional bands of 6 and $10 \mathrm{~kb}$ were seen. Lisl transcripts are $8 \mathrm{~kb}$ in length and are expressed in all tissues examined with somewhat lower levels in spleen, liver and testis. The ORF probe detected mainly 3 and $8 \mathrm{~kb}$ messages, with fainter bands migrating at 4.4 and $6 \mathrm{~kb}$ in some tissues (e.g., kidney). The $3 \mathrm{~kb}$ transcript was expressed in all tissues except for the brain, with highest levels in liver and testis. This transcript arises by alternative splicing and polyadenylation (Reiner, unpublished data).

\section{Expression pattern of Lis 1 in the developing nervous system}

Sequence comparison and genetic mapping to syntenic chromosomal positions indicated that the Lisl gene is the mouse homolog of human LISI involved in Miller-Dieker lissencephaly. Therefore, expression analyses were carried out by in situ hybridization using a Lisl-specific riboprobe ("Lisl probe" in Fig. 2B). Control hybridizations using sense riboprobe gave no signal (Fig. 6A). In E10.5-E14 embryos Lis I mRNA was very abundant in the developing central and peripheral nervous systems, including the neuroepithelium of the fore-, mid-, and hindbrain, the spinal cord, the dorsal root ganglia (Fig. 4A,B), and the cranial ganglia. In addition, Lis 1 was broadly expressed at low levels in mesodermal tissues such as lateral plate-derived structures (Fig. 4A), and craniofacial- and limb bud mesenchyme (not shown).

The cerebral cortex is the tissue most severely affected in 

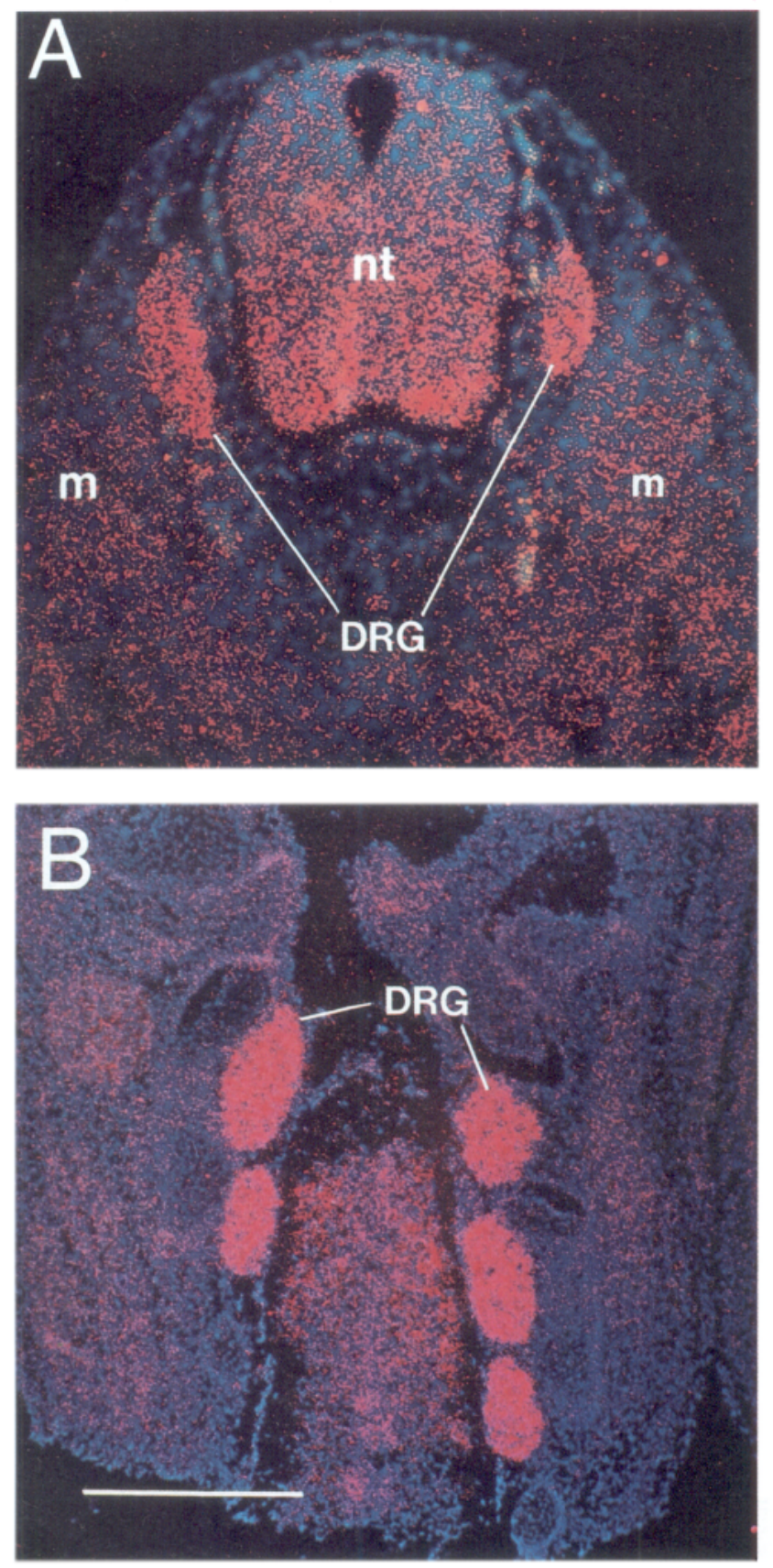

Figure 4. Expression of LisI in the mouse neural tube and in dorsal root ganglia. Micrographs show double exposures with the red color representing signal from in situ hybridization and blue showing nuclei stained with Hoechst 33258 dye. A, Transverse section through a 12.5 p.c. (E12.5) embryo. Highest expression is observed in the ventral part of the neural tube $(n t)$ and in the dorsal root ganglia $(D R G)$. Lower signal is seen in the premuscle mesodermal condensation $(m) . B$, Coronal section through the cervical region of an E14 embryo. Lis1 mRNA is abundant in the DRGs. Scale bar, $500 \mu \mathrm{m}$.

individuals with Miller-Dieker lissencephaly. Cerebral cortical neurons are generated from the ventricular zone of the telencephalon. Postmitotic neurons exit the ventricular zone and eventually form the marginal zone (layer 1; see Fig. 6B). Later born neurons migrate radially to form the cortical plate. The later arriving neurons migrate subsequently through layer 6 and form layer 5 . The later developing layers $2-4$ are formed by the same inside-first mechanism, thus the younger layers are positioned
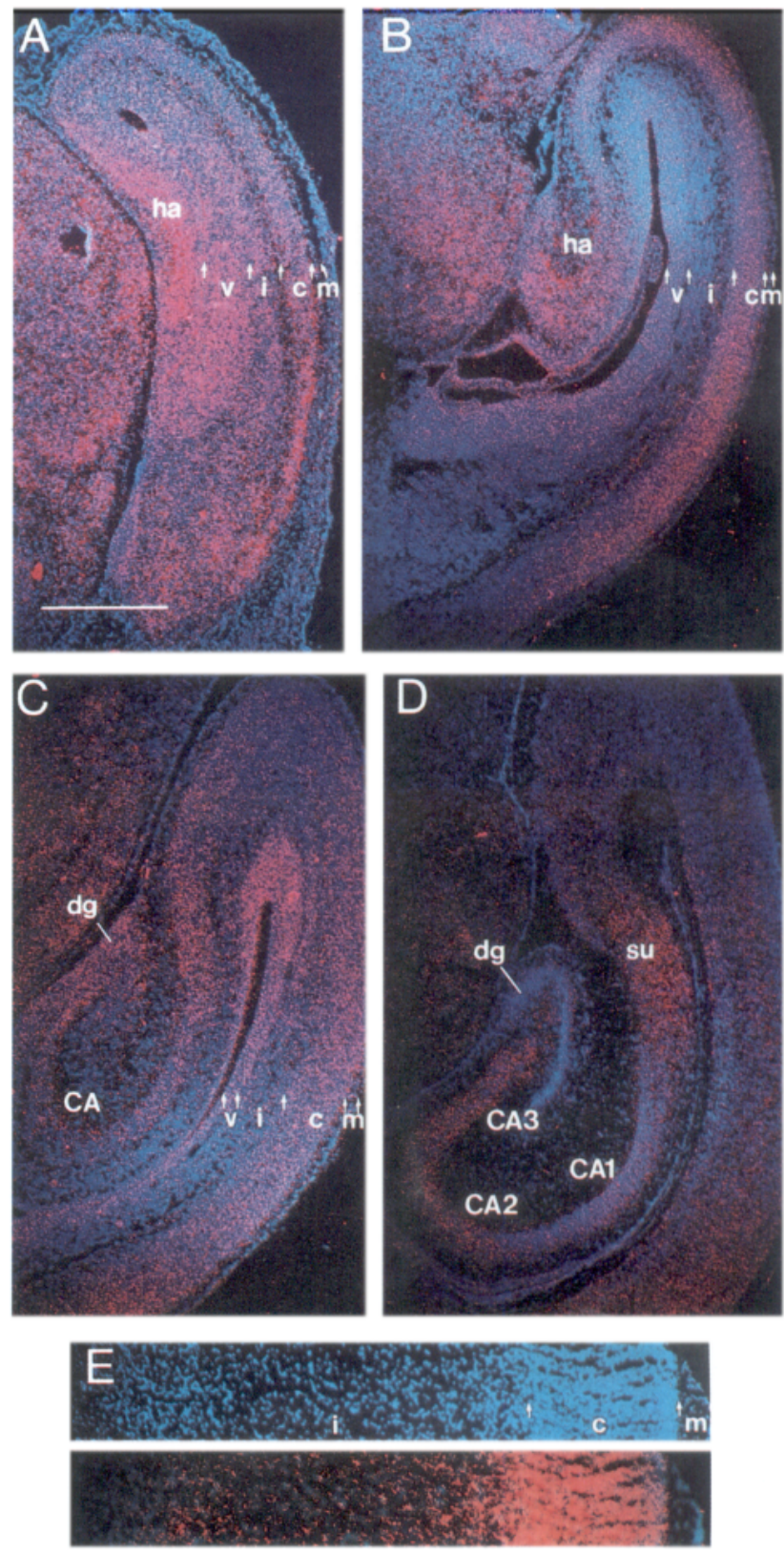

Figure 5. Expression of Lisl in the developing mouse cortex and hippocampus, and expression of LISI in human fetal cortex. Coronal sections through the left ventricle of the mouse forebrain $(A-D)$; rostral is on top. A, At E15.5 the developing brain shows broad Lis/ expression with elevated levels in the hippocampal anlage (ha). B, At E17 LisI expression is observed in the hippocampal anlage, the ventricular zone $(v)$ and the cortical plate $(c)$. Low signal is observed in the intermediate zone (i). C, At E18 the dentate gyrus $(d g)$ is apparent and is Lisl positive. $D$, Expression in the dentate gyrus is attenuated by postnatal day 5. At this stage the cornu ammonis $(C A)$ is positive for Lisl in regions 2 and 3, and LisI mRNA is also detected in the subiculum (su). Note that the size of the ventricular zone $(v)$ decreases during development while the cortical plate $(c)$ increases in size (boundaries marked by arrows). E, Coronal section through the cortex of a 19 week old human fetus at the level of the striatum. The upper panel shows a Hoechst stain. The lower panel shows that the cortical plate $(c)$ is strongly LISI positive, whereas the intermediate zone (i) shows substantially less signal and the molecular layer $(m)$ is negative. Scale bar, $500 \mu \mathrm{m}$. 

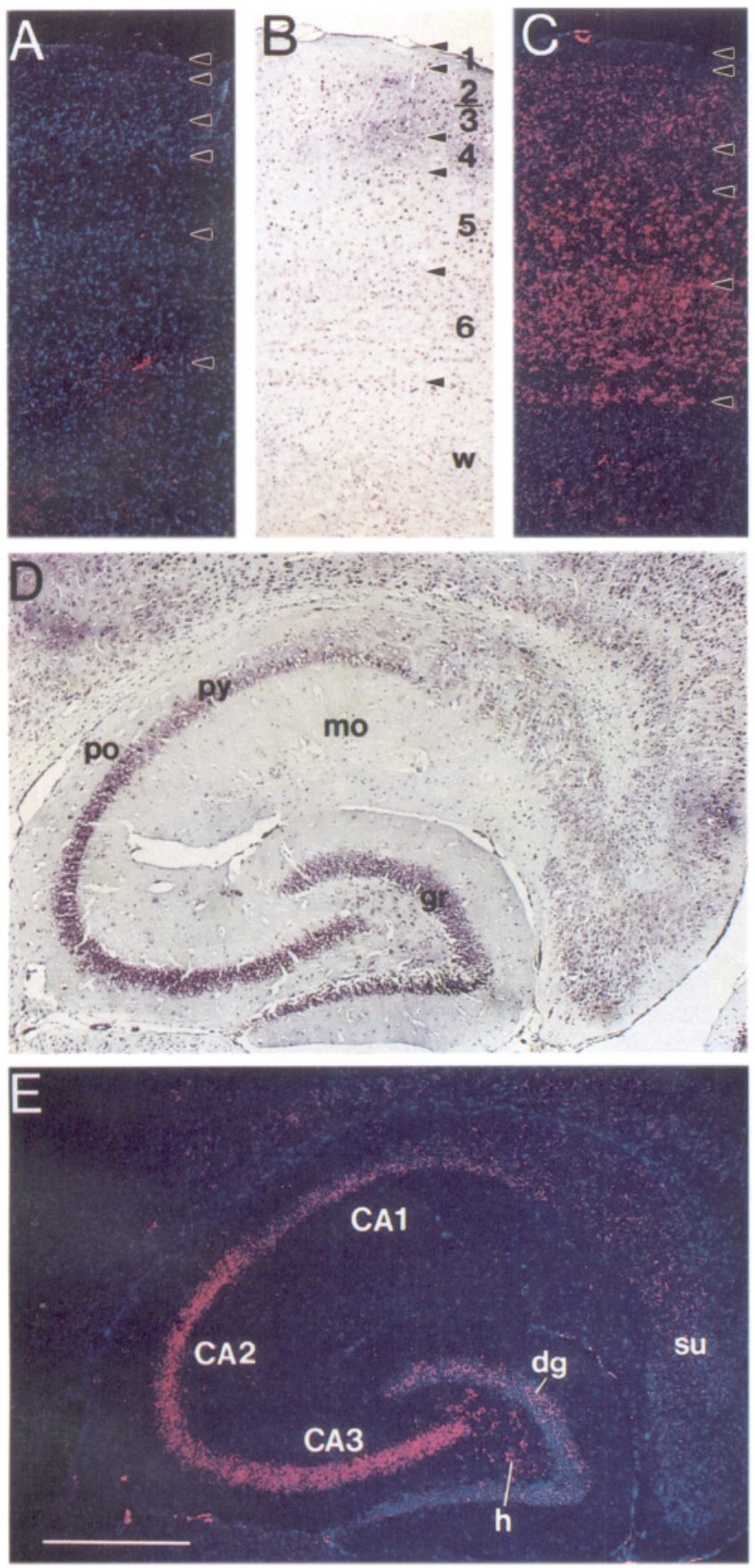

Figure 6. Expression of the Lisl gene in the adult mouse brain. All figures display horizontal sections. $A-C$ show the cerebral cortex in adjacent sections. A, Section hybridized with sense riboprobe. Nisslstaining in $B$ reveals the six cortical layers. $C$, Expression of Lisl transcript is detected in layers $2-6$ with particularly higher levels in layers 5 and $6 . D$ and $E$. Hippocampal formation. $D$, Nissl-stained section adjacent to the section shown in E. Lis I expression is detected in the pyramidal cells of regions $\mathrm{CA} 2$ and $\mathrm{CA} 3$ of the hippocampus and in the hilus $(E) . C A$, cornu ammonis; $d g$, dentate gyrus; $h$, hilus; $m o$, molecular layer; po, polymorphic cell layer; $p y$, pyramidal cell layer; $s u$, subiculum; $w$, white matter. Magnification in $A-E$ is identical. Scale bar, $500 \mu \mathrm{m}$.
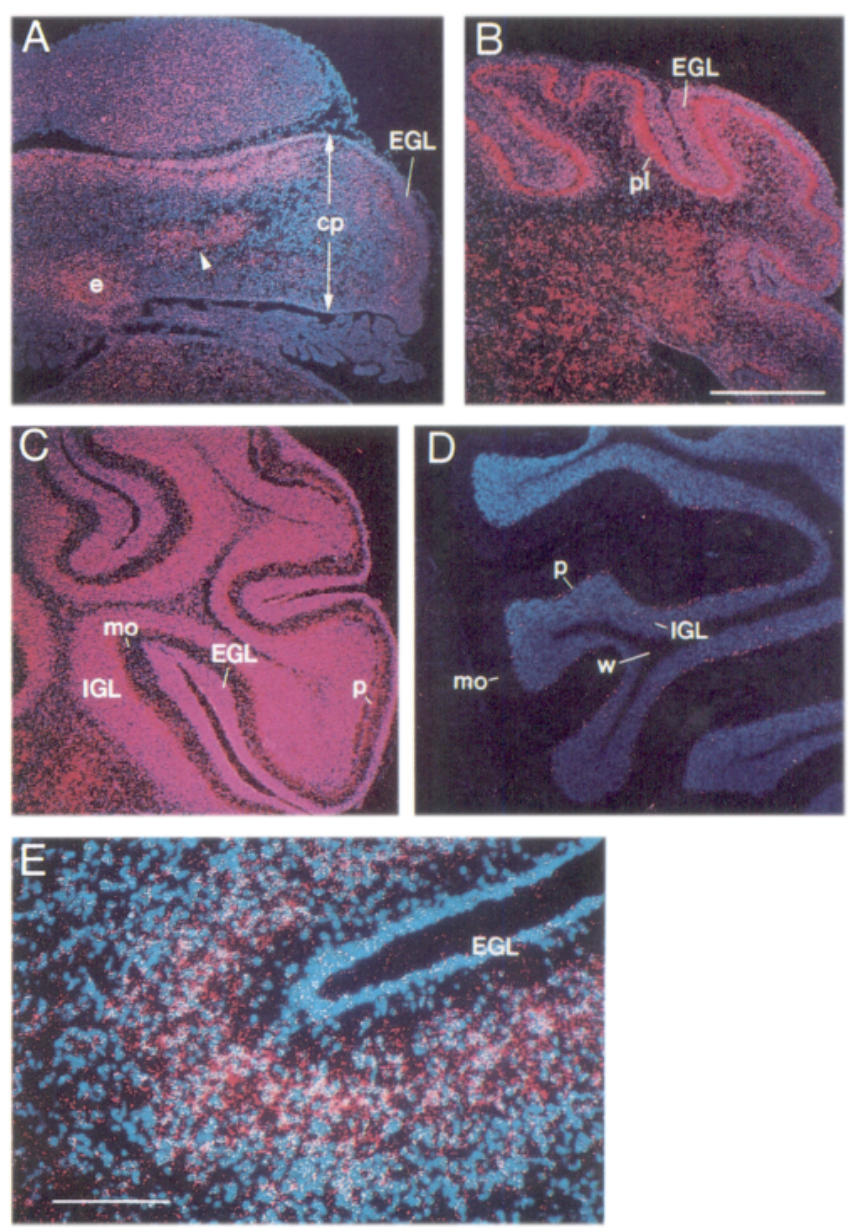

Figure 7. Expression of the murine LisI gene and human LISI gene in the developing cerebellum of mouse and human. $A-D$, Coronal sections through mouse cerebellum. A, Cerebellar plate $(c p)$ of a mouse one day before birth (E18). A distinct expression pattern is seen in the ependymal (ventricular) zone $(e)$ and the external granular layer $(E G L)$. $B$, At P5 strongest expression is seen at the border of the EGL and the future Purkinje cell layer $(p l)$. $C$, At P10, the granule cells which have migrated through the Purkinje cell layer show strong expression in the internal granular layer $(I G L)$. The Purkinje cells $(p)$ and the later migrating granule cells, still located in the EGL, also strongly express Lisl. In the adult $(D)$ expression in the IGL is very low but is still detected in the Purkinje cells. E, Section through the developing cerebellum of a 19 week old human fetus. LISI transcripts are found in a broad zone containing granule cells and Purkinje cell precursors. Scale bars: $A-D, 500 \mu \mathrm{m} ; E, 80 \mu \mathrm{m}$.

outside of the older ones (Berry and Rogers, 1965; Shoukimas and Hinds, 1978; Miller, 1985).

In the cerebral cortex and the hippocampus, Lis I was strongly expressed throughout development. By E15.5, Lisl was expressed in the ventricular and intermediate zones, and the cortical plate, but not in the marginal zone (Fig. 5A). By E16 and E17 a more restricted signal was detected encompassing the ventricular zone and the cortical plate with the emerging intermediate zone being only weakly positive (Fig. 5B). As development of the brain proceeded, Lisl expression declined in the ventricular zone along with reduction in size of this structure and became restricted to the regions forming the cerebral cortex (Fig. $5 B, C$ ). The murine adult cortex consists of six layers, as visualized by Nissl staining (Fig. 6B), with five of the six layers showing Lis 1 hybridization (Fig. 6C). Lisl mRNA was most 
abundant in layers 5, 6, and the subplate (Fig. 6C), which are established prior to layers 2-4 during development. Layers $2-4$ also showed pronounced hybridization, but at somewhat lower levels than the deep layers. Low levels of expression were detectable in the white matter (Fig. 6C). In layer 1 (marginal zone) no hybridization was observed.

To complement the studies in the mouse, we have examined the developing cerebral cortex of a 19 week old normal human fetal brain for LISI expression. As in the corresponding stages of mouse (E16; see O'Rahilly and Muller, 1992; Bayer et al., 1993), the cortical plate, the marginal and intermediate zones are present and distinct by week 19 . Reminiscent of the mouse (Fig. 5A,B), we found that LISI was highly expressed in the cortical plate and at lower levels in the intermediate zone of human fetal brain (Fig. $5 E$ ).

The hippocampal anlage of the mouse was apparent by embryonic day 15 . Elevated expression of Lis 1 was detected in the hippocampal primordium by E15.5 (Fig. 5A). During the following days, the involution of the lateral cortical plate and the emergence of mature features of hippocampal structures becomes evident. The prospective cornu ammonis, which is a direct continuation of the cortical plate, showed distinct expression of Lisl (Fig. 5B). Lisl expression in the dentate gyrus was visible by E18 (Fig. $5 C$ ), but later, expression in the gyrus appeared to be markedly reduced especially with reference to CA2 and CA3 regions (Figs. 5D, 6E). The subiculum, a transitional zone between the neocortex and the archicortex of the hippocampus, expressed Lisl by P5 (Fig. 5D) but expression was substantially reduced at later times (Fig. $6 E$ ). In the adult brain, the pyranidal cell layer of regions $\mathrm{CA} 2$ and $\mathrm{CA} 3$ was strongly positive for Lis I, whereas in the CA1 region markedly reduced levels of expression were observed (Fig. $6 E$ ). Punctate hybridization was detected in the hilus of the dentate gyrus, but only a low level of Lis 1 signal was detected in the dentate gyrus itself.

Most of the cerebellar neurons (e.g., Purkinje cells) are generated from the ventricular zone and migrate outward to their appropriate positions. However, the granule cells arise from a distinct proliferative region, the external granular layer (EGL). EGL cells, in turn, derive from a migratory population of cells that are born in and leave the ventricular zone of the alar plate of the fourth ventricle and move around the rhombic lip to eventually cover the entire surface of the cerebellum (Miale and Sidman, 1961; Altman and Bayer, 1978). Once the EGL is formed, cells in it proliferate, leave the cell cycle, and migrate inward through the Purkinje cell layer and along Bergmann glial fibers to give rise to the internal granule cell layer (IGL) (Rakic, 1971; Chuong, 1990; Millen et al., 1994; Sotelo et al., 1994).

Expression of Lis 1 in the cerebellum was transient. The first distinct pattern of expression in the cerebellum was seen by E16 in the ventricular zone and in the EGL (not shown). By E17 and E18, a more pronounced expression was seen in both the ventricular zone and the EGL (Fig. 7A). Furthermore, there were distinct patches of Lis 1 -positive cells between the ependymal zone and the EGL, possibly representing outwardly migrating neuronal precursors (Fig. 7A, arrowhead). By P3-P5, when cells in the EGL are mitotically active and beginning to generate granule neurons, strong Lisl expression was detected at the boundary between Purkinje cell layer and molecular layer (Fig. $7 B$ ). At P10, Lisl expression was very pronounced in the Purkinje cells which can now be detected in a characteristic single layer (Fig. 7C). Expression was also apparent in the EGL and in postmigratory granule neurons that had migrated inward through the Purkinje layer and into the internal granule layer (IGL). Also, note the emerging molecular layer, located between the Purkinje cell layer and the residual EGL. This molecular zone was largely devoid of Lis I expression: the low levels seen may derive from migrating granule cell neurons (Fig. 7C). Between P20 and P25, developmental stages at which the external granule layer has disappeared, Lisl expression was greatly reduced (not shown). In the cerebellum of the adult mouse, the Lis 1 gene was expressed in a punctate manner in Purkinje cells (Fig. 7D), and more weakly in the IGL.

LISI was distinctly expressed in the cerebellum of a 19 week old human fetus (Fig. $7 E$ ). By 19 weeks of development, the EGL is established and EGL neurons have begun to migrate inward (O'Rahilly and Muller, 1992). There is a distinct layer of cells located on the pial surface which display mitotic figures and represent the proliferating external granule cell layer (Fig. $7 E$ ). By that time of development, EGL cells have already begun their inward migration. Due to the absence of a distinct histological stratification at this developmental stage, it was not possible to determine which cells contained LISI mRNA, but in analogy to the mouse, expressing cells may include inward-migrating granule cells and Purkinje cells.

\section{Discussion}

The LIS gene family

Mapping of the mouse Lis cDNA clones revealed that these genes constitute a gene family. Two mouse cDNAs were cloned (Lisl and Lis3-4), and three genetic loci were identified (Lisl, Lis3 and Lis4). In human, two cDNAs were previously isolated and mapped to human chromosomes 17 and 2 (LISI and LIS2) (Reiner et al., 1993). Murine Lisl is likely to represent the homolog of human LISI because sequences of the coding and noncoding regions are very similar, and furthermore the genes map to syntenic chromosomal positions. In addition, expression patterns are similar. Amino acid sequence identity of $>99 \%$ between the human LISI and the murine and bovine homologs (Hattori et al., 1994) demonstrate a unique protein type with little species variation. This finding suggests that these proteins must perform an important, conserved function. While such identity was seen with other proteins it must be stated that this high degree of similarity is unusual. Additionally, conservation of sequences in the $5^{\prime}$ and $3^{\prime}$ untranslated regions of LISI and its mouse homolog suggests common regulatory mechanisms.

The independent discovery of various aspects of LISI is fascinating. The initial characterization of this disease-associated gene (Reiner et al., 1993) identified protein sequence motifs found in protein/protein interactions (Duronio et al., 1992; Neer et al., 1993, 1994). A clearly demonstrated example of LIS 1 protein participating in a complex is provided by brain plateletactivating factor acetylhydrolase, an enzyme in which LIS 1 protein is a subunit of a ternary complex (Hattori et al., 1994). This enzyme inactivates platelet-activating factor (PAF) which has both neuronal differentiation properties (Kornecki and Ehrlich, 1988; Ved et al., 1991) and neuronal messenger activity (Bito et al., 1992; Clark et al., 1992; Kato et al., 1994).

LIS1 is a hemizygous locus. In view of its gene product functioning as a subunit in an enzyme, hemizygosity is not unexpected since reducing the cellular concentration of LIS I protein by half would reduce the level of assembled, functional enzyme. PAF acetylhydrolase may not be the only multisubunit protein containing LIS1 protein. In this case, a reduction in the cellular concentration of LIS1 protein may have multiple effects, and the 
inability to inactivate PAF being only one facet of the MillerDieker syndrome. An additional aspect to consider is that Lis3-4 is also expressed in the brain, albeit at much lower levels than Lis 1 . Nonetheless, the amino acid sequence conservation of the two gene products raises the possibility that they can mutually substitute each other.

\section{Lis l expression: functional implications and relationship to Miller-Dieker lissencephaly}

Miller-Dieker lissencephaly patients exhibit severe mental retardation, hypotonia, spastic paralysis, and infantile spasms. The cortex of these individuals consists of four layers (see Stewart et al., 1975). In the mouse, expression in the fetal and postnatal cerebrum was most distinct in the ventricular zone, the cortical plate, and in the developing cortex. Likewise, the human gene was highly expressed in the cortical plate. In the adult mouse, Lis 1 transcripts were most abundant in neurons of layers 5 and 6 of the cortex. Based on histologic investigations the prevailing view is that Miller-Dieker lissencephaly is the result of neuronal migration defects (e.g., Barth, 1987; Dobyns 1987). The broad expression of LisI during embryogenesis is consistent with this idea; regions in which neurons migrate express this gene. It is worth noting that LisI was expressed in the neuroepithelium and later in its derivative, the ventricular zone. There is evidence for cell migration within the ventricular zone (Fishell et al., 1993).

How could a loss of PAF acetyl hydrolase activity result in abnormal neuronal migration? PAF is a phospholipid signaling molecule for which a specific G-protein linked transmembrane receptor has been isolated (Honda et al., 1991). Therefore, PAF appears to be an extracellular signal binding to the extracellular domain of PAF receptor. Treatment of neuroblastoma cells with PAF results in an increased intracellular calcium level (Kornecki and Ehrlich, 1988; Yue et al., 1993). An increase in calcium may affect the organization of the cytoskeleton which could alter the migratory behavior of cells (Komuro and Rakic, 1992, 1993; Rakic et al., 1994). How a reduction of PAF acetylhydrolase activity in Miller-Dieker patients can affect such a process is unclear. The paradox which needs to be resolved is that the PAF acetylhydrolase containing Lis 1 protein resides inside cells but PAF binds to the extracellular side of its receptor.

Lis 1 was expressed in the CA2 and CA3 regions of the hippocampus and at lower levels in $\mathrm{CA} 1$, the subiculum and the dentate gyrus. Miller-Dieker lissencephaly patients suffer from seizures possibly reflecting hippocampal defects (Lothman et al., 1992; Sutula et al., 1992; Swann et al., 1992). This could involve abnormal levels of PAF. This signaling molecule mobilizes intracellular calcium in hippocampal neurons (Bito et al., 1992), enhances hippocampal excitatory synaptic transmission (Clark et al., 1992), and participates in long-term potentiation in the CA1 region (Kato et al., 1994).

In the developing cerebellum of both mouse and human, a distinct zone of Lis1 expression encompassed the inward-migrating external granule cell neurons and possibly also the Purkinje cell precursors. In situ hybridization data in human do not provide sufficient spatial resolution to accurately determine which cells in the cerebellum expressed LISI and therefore, it is not clear whether migrating cells and/or the cells surrounding them expressed this gene. Abnormalities in the cerebellum of lissencephaly patients have been noted (Miller, 1963; Stewart et al., 1975). Stewart et al. (1975) have described a lissencephaly patient whose cerebellum was reduced in size and showed mild defects in the convolutional folding. More importantly the ex- ternal granular layer was absent and the internal granular layer greatly reduced. Since LisI is transiently expressed in granule cells a function of the Lisl gene product in granule cell migration can be suggested.

In human, mutations in LISI seem to be the major cause for Miller-Dieker lissencephaly, since at least $90 \%$ of patients have deletions in this region. In addition to LISI, mutations in other loci can also cause lissencephaly (reviewed in Dobyns et al., 1993). reeler, an autosomal recessive mouse mutant, also affects the organization of the cerebral cortex (Caviness and Rakic, 1978). Since reeler maps to mouse chromosome 5 it is not related to the known lissencephaly loci. Our understanding of the pathophysiological mechanisms underlying lissencephaly is rudimentary at this time. However, the present study reveals a clear correlation between tissucs affected by the genetic defect and sites of expression in mouse and human. This suggests that the mouse is a suitable organism for development of an animal model and for future functional studies of the LIS proteins. This unique disorder provides an important tool for molecular dissection of components involved in this disease and possibly for the study of mechanisms of neuronal specification and migration which appear abnormal in lissencephalic patients.

\section{References}

Aicardi J (1989) The lissencephaly syndromes. Int Pediatr 4:118-126. Aicardi J (1991) The agyria-pachygyria complex: a spectrum of cortical malformations. Brain Dev 13:1-8.

Altman J, Bayer SA (1978) Prenatal development of the cerebellar system in the rat. I. Cytogenesis and histogenesis of the deep nuclei and the cortex of the cerebellum. J Comp Neurol 179:23-48.

Barth PG (1987) Disorders of neuronal migration. Can J Neurol Sci 14:1-16.

Bayer SA, Altman J, Russo RJ, Zhang X (1993) Timetables of neurogenesis in the human brain based on experimentally determined patterns in the rat. Neurotoxicology 14:83-144.

Berry M, Rogers AW (1965) The migration of neuroblasts in the developing cerebral cortex. J Anat 99:691-709.

Bito H, Nakamura M, Honda Z, Izumi T, Iwatsubo T, Seyama Y, Ogura A, Kudo Y, Shimizu, T (1992) Platelet-activating factor (PAF) receptor in rat brain: PAF mobilizes intracellular $\mathrm{Ca}^{2+}$ in hippocampal neurons. Neuron 9:285-294.

Bladon TS, McBurney MW (1991) The rodent B2 sequence can affect expression when present in the transcribed region of a reporter gene Gene 98:259-263.

Buchberg AM, Bedigian HG, Jenkins NA, Copeland NG (1990) Evi2 , a common integration site involved in murine myeloid leukemogenesis. Mol Cell Biol 10:4658-4666.

Caviness VS, Rakic P (1978) Mechanisms of cortical development: a vicw from mutations in mice. Annu Rev Neurosci 1:297-326.

Chuong CM (1990) Differential roles of multiple adhesion molecules in cell migration. granule cell migration in cerebellum. Experientia 46:892-899.

Clark GD, Happel LT, Zorumski CF, Bazan NG (1992) Enhancement of hippocampal excitatory synaptic transmission by platelet-activating factor. Neuron 9:1211-1216.

Dieker H, Edwards RH, ZuRhein G, Chou SM, Hartman HA, Opitz JM (1969) The lissencephaly syndrome. Birth Defects V 2:53-64.

Dietrich W, Katz H, Lincoln SE, Shin HS, Friedman J, Dracopoli NC Lander ES (1992a) A genetic map of the mouse suitable for typing intraspecific crosses. Genetics 131:423-447.

Dietrich W, Miller J, Katz H, Joyce D, Steen R, Lincoln S, Daly M, Reeve MP, Weaver A, Anagnostopoulos P, Goodman N, Dracopoli N, Lander ES (1992b) In: Genetic maps (O’Brien SJ, ed). Cold Spring Harbor, NY: Cold Spring Harbor Laboratory.

Dobyns WB (1987) Development aspects of lissencephaly and the lissencephaly syndromes. In: Genetic aspects of developmental pathology, pp 225-241. New York: March of Dimes Birth Defects Foundation.

Dobyns WB, Reiner O, Carrozzo R, Ledbetter DH (1993) Lissencephaly: a human brain malformation associated with deletion of the 
LIS1 gene located at chromosome 17p13. I Am Med Assoc 270: 2838-2842.

Duronio RJ, Gordon JI, Boguski MS (1992) Comparative analysis of the $\beta$ transducin family with identification of several new members including PWP1, a nonessential gene of Saccharomyces cervisiae that is divergently transcribed from NMT1. Proteins 13:41-56.

Fishell G, Mason CA, Hallen ME (1993) Dispersion of neurond progenitors within the germinal zones of the forebrain. Nature 362:636638

Fu Y-H, Friedman DL, Richards S, Pearlman JA, Gibbs RA, Pizzuti A, Ashizawa T, Perryman MB, Scarlato G, Fenwick RG, Caskey CT (1993) Decreased expression of myotonin-protein kinase messenger RNA and protein in adult form of myotonic dystrophy. Science 260 : 235-238.

Hattori M, Adachi H, Tsujimoto M, Arai N, Inoue K (1994) MillerDieker lissencephaly gene encodes a subunit of brain platelet-activating factor acetylhydrolase. Nature 370:216-218.

Heidmann O, Buonanno A, Geoffroy B, Robert B, Guenet JL, Merlie JP, Changeux JP (1986) Chromosomal localization of muscle nicotinic acetylcholine receptor genes in the mouse. Science 234:866868.

Honda Z, Nakamura M, Miki I, Minami M, Watanabe T, Seyama Y, Okado H, Toh H, Miyamoto T, Shimizu T (1991) Cloning by functional expression of platelet-activating factor receptor from guineapig lung. Nature 349:342-346.

Kato K, Clark GD, Bazan NG, Zorumski CF (1994) Platelet-activating factor as a potential retrograde messenger in CAl hippocampal longterm potentiation. Nature 367:175-179.

Komurn H, Rakic P (1992) Selective role of N-type calcium channels in neuronal migration. Science 257:806-809.

Komuro H, Rakic P (1993) Modulation of neuronal migration by NMD $\Lambda$ receptors. Science 260:95-97.

Kornecki E, Ehrlich YH (1988) Neuroregulatory and neuropathological actions of the ether-phospholipid platelet-activating factor. Science 240:1792-1794.

Kuchelmeister K, Bergmann M, Gullotta F (1993) Neuropathology of lissencephalies. Childs Nerv Syst 9:394-399.

Lothman EW, Stringer JL, Bertram EH (1992) The dentate gyrus as a control point for seizures in the hippocampus and beyond. Epilepsy Res [Suppl] 7:301-313.

Ma Q, Alder H, Nelson KK, Chatterjee D, Gu Y, Nakamura T, Canaani E, Croce CM, Siracusa LD, Buchberg AM (1993) Analysis of the murine All-1 gene reveals conserved domains with human ALL-1 and identifies a motif shared with DNA methyltransferases. Proc Natl Acad Sci USA 90:6350-6354.

Marini JC, Nelson KK, Battey J (1993) The pituitary hormones arginine vasopressin-neurophysin II and oxytocin-neurophysin I show close linkage with interleukin-I on mouse chromosome 2. Genomics $15: 200-202$.

Miale I, Sidman RL (196I) An autoradiographic analysis of histogenesis in the mouse cerebellum. Exp Neurol 4:277-296.

Millen KJ, Wurst W, Herrup K, Joyner AL (1994) Abnormal embryonic cerebellar development and patterning of postnatal foliation in two mouse Engrailed-2 mutants. Development 120:695-705.

Miller JQ (1963) Lissencephaly in two siblings. Neurology 13:841850.

Miller MW (1985) Cogeneration of retrogradely labeled corticocortical projection and GABA-immunoreactive local circuit neurons in cerebral cortex. Dev Brain Res 23:187-192.

Neer E, Schmidt CJ, Smith T (1993) LIS is more. Nat Genet 5:3-4.

Neer EJ, Schmidt CJ, Nambudripad R, Smith TF (1994) The ancient regulatory-protein family of WD-repeat proteins. Nature 371:297300 .

O'Rahilly R, Muller F (1992) Human embryology and teratology. New York: Wiley-Liss.

Putt FA (1972) Manual of histopathological staining methods, pp 304305. New York: Wiley

Rakic P (1971) Neuron-glia relationship cluring granule cell migration in developing cerebellar cortex. A Golgi and electron microscope study in Macacus rhesus. J Comp Neurol 141:283-312.

Rakic P, Cameron RS, Komuro H (1994) Recognition, adhesion, transmembrane signaling and cell motility in guided neuronal migration. Curr Opin Neurobiol 4:63-69.

Reiner O, Carrozzo R, Shen Y, Whenert M, Faustinella F, Dobyns WB, Caskey CT, Ledbetter DH (1993) Isolation of a Miller-Dieker lissencephaly gene containing $G$ protein $\beta$-subunit-like repeats. Nature 364:717-721

Sambrook S, Fritisch EI, Maniatis T (1989) Molecular cloning: a laboratory manual. Cold Spring Harbor, NY: Cold Spring Harbor Lab. oratory.

Scott J, Selby M, Urdea M, Quiroga M, Bell GI, Rutter WJ (1983) Isolation and nucleotide sequence of a CDNA encoding the precursor of mouse nerve growth factor. Nature 301:538-540.

Shoukimas GM, Hinds JW (1978) The development of the cerebral cortex in the embryonic mouse: an electron microscopic serial section analysis. J Comp Neurol 179:795-830.

Siracusa LD, Jenkins NA, Copeland NG (1991) Identification and applications of repetitive probes for gene mapping in the mouse. Genetics 127:169-179.

Sotelo C, Alvarado-Mallart RM, Frain M, Vernet M (1994) Molecular plasticity of adult Bergmann fibers is associated with radial migration of grafted Purkinje cells. J Neurosci 14:124-133.

Stewart RM, Richman DP, Caviness VS (1975) Lissencephaly and Pachygyria. Acta Neuropathol 31:1-12.

Sundin OH, Busse HG, Rogers MB, Gudas LJ, Eichele G (1990) Region-specific expression in early chick and mouse embryo of Ghox$l a b$ and $H o x$ 1.6, vertebrate homeobox-containing genes related to Drosophila labial. Development 108:47-58.

Suter U, Moskow JJ, Welcher AA, Snipes GJ, Kosaras B, Sidman RL, Buchberg AM, Shooter EM (1992) A leucine-to-proline mutation in the putative first transmembrane domain of the 22-kD peripheral myelin protein in the trembler-J mouse. Proc Natl Acad Sci USA 89: $4382-4386$.

Sutula TP, Golarai G, Cavazos J (1992) Assessing the functional significance of mossy fiber sprouting. Epilepsy Res [Suppl] 7:251-259

Swann JW, Smith KL, Gomez CM, Brady RJ (1992) The ontogeny of hippocampal local circuits and focal epileptogenesis. Epilepsy Res [Suppl] 9:115-125.

Ved HS, Gustow E, Pieringer RA (1991) Regulation of neuronal differentiation in neuron-enriched primary cultures from embryonic rat cerebra by platelet activating factor and the structurally related glycerol ether lipid, dodecylglycerol. J Neurol Res 30:353-358.

Weydert A, Daubas P, Caravatti M, Minty A, Bugaisky G, Cohen A, Robert B, Buckingham M (1983) Sequential accumulation of mRNAs encoding different myosin heavy chain isoforms during skeletal muscle development in vivo detected with a recombinant plasmid identified as coding for an adult fast myosin heavy chain from mouse skeletal muscle. J Biol Chem 258:13867-13874.

Yue TL, Lysko PG, Friedman E, Feuerstein G (1993) Platelet activating factor receptor-mediated signal transduction mechanism in neurohybrid cells. In: Platelet activating factor receptor (Shukla SD, ed), pp 93-100 Boca Raton, FL: CRC. 